\title{
Persée
}

\author{
http://www.persee.fr
}

\section{Les mudéjars de la couronne d'Aragon}

\author{
M.- Teresa Ferrer i Mallol \\ Ferrer i Mallol M-Teresa, . Les mudéjars de la couronne d'Aragon. In: Revue du monde musulman et de la \\ Méditerranée, №63-64, 1992. Minorités religieuses dans l'Espagne médiévale. pp. 179-194.
}

Voir l'article en ligne

\section{Avertissement}

L'éditeur du site " PERSEE » - le Ministère de la jeunesse, de l'éducation nationale et de la recherche, Direction de l'enseignement supérieur, Sous-direction des bibliothèques et de la documentation - détient la propriété intellectuelle et les droits d'exploitation. A ce titre il est titulaire des droits d'auteur et du droit sui generis du producteur de bases de données sur ce site conformément à la loi n`98-536 du 1 er juillet 1998 relative aux bases de données.

Les oeuvres reproduites sur le site «PERSEE » sont protégées par les dispositions générales du Code de la propriété intellectuelle.

Droits et devoirs des utilisateurs

Pour un usage strictement privé, la simple reproduction du contenu de ce site est libre.

Pour un usage scientifique ou pédagogique, à des fins de recherches, d'enseignement ou de communication excluant toute exploitation commerciale, la reproduction et la communication au public du contenu de ce site sont autorisées, sous réserve que celles-ci servent d'illustration, ne soient pas substantielles et ne soient pas expressément limitées (plans ou photographies). La mention Le Ministère de la jeunesse, de l'éducation nationale et de la recherche, Direction de l'enseignement supérieur, Sous-direction des bibliothèques et de la documentation sur chaque reproduction tirée du site est obligatoire ainsi que le nom de la revue et- lorsqu'ils sont indiqués - le nom de l'auteur et la référence du document reproduit.

Toute autre reproduction ou communication au public, intégrale ou substantielle du contenu de ce site, par quelque procédé que ce soit, de l'éditeur original de l'oeuvre, de l'auteur et de ses ayants droit.

La reproduction et l'exploitation des photographies et des plans, y compris à des fins commerciales, doivent être autorisés par l'éditeur du site, Le Ministère de la jeunesse, de l'éducation nationale et de la recherche, Direction de l'enseignement supérieur, Sous-direction des bibliothèques et de la documentation (voir http://www.sup.adc.education.fr/bib/) ). La source et les crédits devront toujours être mentionnés. 


\section{Maria Teresa Ferrer i Mallol}

\section{LES MUDÉJARS DE LA COURONNE D'ARAGON}

\section{Origine de la population mudéjare}

Après trois siècles de domination islamique ${ }^{1}$, les minuscules Etats chrétiens pyrénéens, nés de la révolte indigène, parfois sous la protection de l'Etat franc voisin, ou par suite de son intervention directe, commencèrent, à la fin du XI et durant le XII ${ }^{e}$ siècles, une grande expansion territoriale qui les conduisit d'abord jusqu'à la vallée de l'Èbre et ensuite, le fleuve franchi, jusqu'à la zone de la province actuelle de Teruel, dans le cas aragonais, jusqu'à Lérida et Tortosa, dans le cas catalan ${ }^{2}$.

L'expansion du XII' siècle s'effectua en admettant le maintien sur place d'une partie de la population musulmane, qui accepta de vivre sous la domination chrétienne. Seule choisit l'exil la classe dirigeante, puissants, grands propriétaires et notabilités de la religion et de la culture. La possibilité de rester facilita la reddition de nombreuses localités, ce qui allégea l'effort militaire des chrétiens, pallia le manque de potentiel démographique de ceux-ci pour repeupler le territoire conquis et assura la continuité de l'agriculture et de l'activité économique.

Le processus de conquête et de repeuplement de la vallée de l'Èbre peut être suivi dans la collection de documents que lui a consacré J. M. Lacarra, et dont la consultation demeure indispensable ${ }^{3}$. Le volume sur les chartes de peuplement annoncé par María Luisa Ledesma en constituera un bon complément. Pour connaître le processus de repeuplement en Catalogne, il est indispensable de consulter la grande cuvre de J. M. Font Rius sur les chartes de peuplement et de franchise de Catalogne 4 .

Au XIII' siècle, l'expansion catalano-aragonaise prit un grand essor grâce à l'œuvre de Jacques I"e. La conquête de Majorque (1239-1241) en constitua le premier maillon, mais nous ne nous en occuperons pas, parce que les musulmans qui demeurèrent dans les Baléares conquises par la force des 
armes n'obtinrent pas la reconnaissance d'un statut propre, et furent réduits en esclavage ou durent se racheter. Le caractère insulaire, et donc plus vulnérable, du nouveau territoire, imposa d'interdire le maintien d'une collectivité qui aurait pu agir comme une cinquième colonnes.

Le deuxième maillon de la grande expansion catalano-aragonaise fut la conquête du royaume de Valence, qui prit plus de temps (1231-1245) . On y suivit de même fréquemment la méthode des pactes pour le maintien de la population musulmane sur ses terres, ce qui laissa les chrétiens en minorité durant les premiers temps et favorisa les grandes révoltes sarrasines de la seconde moitié du XIII' siècle?.

La vision de la société islamique de Valence antérieure à la conquête et l'interprétation de cette dernière ont suscité, entre ceux qui veulent souligner la rupture entre l'état islamique et celui des chrétiens et ceux qui mettent en évidence les éléments de continuité, une polémique où sont intervenus, entre autres, P. Guichard, R. I. Burns, M. de Epalza et M. J. Rubiera. Burns a souligné qu'il avait été mal compris et qu'il ne prend parti pour aucune des deux options, mais pour un moyen terme : transition, transformation et adaptation. Pourtant, les divergences semblent subsister sur certains points particuliers 8 .

La connaissance que nous avons des communautés islamiques résidant dans les Etats de la Couronne catalano-aragonaise, et dont on peut appeler les membres "mudejares", "moros" ou "sarracenos", est très inégale selon les zones et les périodes. Pourtant la bibliographie a beaucoup augmenté ces derniers temps. Les études locales ont proliféré, à la faveur de l'apparition de revues culturelles dans de nombreuses localités et du mécénat des municipalités pour la publication d'une histoire de leur ville. Il en est résulté une meilleure connaissance de différentes aljamas musulmanes, soit dans des études particulières, soit dans des chapitres d'histoires locales. Les congrès internationaux de mudéjarisme tenus à Teruel ont également beaucoup contribué à susciter ces études, comme l'existence de revues spécialisées, telles que "Sharq al-Andalus. Estudios Arabes", qui, en concentrant son attention sur ces régions, a renforcé et complété l'œuvre d'“Al-Andalus" et d'"AlQanțara", qui en a pris la suite. "Sharq Al-Andalus" donne en outre, dans la plupart de ses numéros, une information bibliographique, en général fournie par Mikel de Epalza, F. Franco Sánchez, ou d'autres collaborateurs, et qui constitue une aide inestimable à la recherche.

Je dois modestement ajouter que la concession de trois projets de recherche triennaux à l'équipe que j'ai animée de 1982 à 1992 a également contribué au volume des publications. Les lecteurs seront juges de l'utilité et de la qualité de celles-ci'.

Les cuvres offrant un point de vue général pour toute la Couronne d'Aragon sont, en ce qui concerne le XIV' siécle, celle de J. Boswell, centrée sur une période de conflit, la guerre avec la Castille, dite guerre des deux Pedros, au milieu du siècle ${ }^{10}$, et la première de M. T. Ferrer, qui se limite à l'étude de certains thèmes : ségrégation, liberté religieuse et liberté de mouvement ", et pour le XVe siècle. un article de W. Küchler'2. Il faut consulter également l'état de la question élaboré en 1984 par Mercedes García-Arenal ${ }^{13}$. Sur l'héritage arabe dans les noms de famille de l'ancienne Couronne, quelque peu agrandie vers le Sud, il existe deux travaux de J. Vernet, avec des considérations intéressantes sur la descendance minimale actuelle des morisques ${ }^{14}$. 


\section{Nombre et répartition de la population}

\section{Catalogne}

La population islamique résidant dans le Principat au Bas Moyen Age est très mal connue, bien que nous espérions que la situation change bientôt. Les causes en sont sa moindre importance numérique comparativement à celle de l'Aragon ou du royaume de Valence, et la difficulté à localiser les sources, car, sauf les aljamas musulmanes de Lérida et de Tortosa, qui étaient royales, les autres appartenaient à des seigneuries nobiliaires ou ecclésiastiques, spécialement celles de l'Ordre de l'Hôpital. Quelques sources nobiliaires se trouvent dans les Archives des ducs de Medinaceli, à Séville, tandis que celles de l'Ordre de l'Hôpital, divisées entre Barcelone et Madrid, sont d'un maniement difficile, sauf pour les parchemins, parce que les documents sont très mélangés. Il n'existe aucune étude d'ensemble, exception faite de l'analyse des recensements, et des œuvres générales déjà citées.

La source la plus complète pour connaître la population musulmane résidant en Catalogne est le fogatge de 1496, qui donne un total de 788 feux musulmans. Dans les vigueries où ils résidaient, ils représentent un pourcentage élevé de $25,53 \%$ de la population totale, puisque les feux chrétiens dans les trois vigueries concernées de Montblanc, Lérida et Tortosa s'élevaient à 2295, sur un total de $3083^{15}$. Par contre, les moros ne représentent pas plus de $1,5 \%$ environ de l'ensemble de la population de Catalogne. Il semble que la population islamique ait diminué au cours des XIVe et XVe siècles, spécialement dans les villes de Lérida et de Tortosa, certainement par suite de l'émigration.

Les musulmans étaient concentrés dans les vallées de l'Èbre et de son affluent, le Segre. Dans la zone du Segre, il convient de mettre à part la morería de Lérida, qui avait perdu de sa population au XIVe siécle, et ne comptait plus que 22 feux en 1496. Beaucoup plus importantes étaient les morerías de Serós et d'Aitona, bien qu'il se fût agi de localités moins considérables. L'une et l'autre appartenaient aux Montcada, de même que Fraga et Mequinenza, dont nous parlerons à propos de l'Aragon. P. Sanahuja, Rodrigo Pita Merce, Josep Lladonosa et J. M. Font Rius ont étudié la morería de Lérida, ou certains aspects particuliers de celle-ci ${ }^{16}$. Actuellement, Josefina Mutgé a terminé son étude sur cette aljama au Bas Moyen Age, qui paraîtra en 1992.

Les musulmans se concentraient en bien plus grand nombre dans la vallée de l'Ėbre, où certaines localités, comme Benissanet et Riba-roja, continuaient à n'avoir, au XV' siècle, qu'une population exclusivement islamique. En 1496, Riba-roja, Flix, Vinebre, Ascó, Garcia, Mora, Benissanet, Tivissa, Miravet, Benifallet, Xerta, Tivenys et Tortosa réunissaient 568 des 788 feux musulmans de toute la Catalogne.

Dans cette zone, le Temple d'abord, et ensuite l'Ordre de l'Hôpital possédèrent de vastes domaines : Riba-roja, Flix, Vinebre, Ascó, Benissanet et Miravet, bien que Flix ait été achetée par Barcelone en 1398 et soit devenue baronnie de la ville. D'autres localités, telles Garcia, Mora et Tivissa appartinrent aux Castellvell, ensuite à la baronnie d'Entença et enfin au comté de Prades. Benifallet, Xerta et d'autres lieux du delta de l'Ebre appartenaient au territoire général de Tortosa. J. M. Font i Rius d'abord, ensuite Carmel Biamés et plus récemment Manuel Romero et Pascual Ortega ont publié des articles et des livres sur les musulmans et les morisques de cette contrée. P. Ortega est en train d'achever son étude, vaste et documentée, qui constituera sa thèse de doctorat, sur les morisques de la zone, où il remonte à la période médiévale, depuis la conquête chrétienne ${ }^{17}$.

L'aljama sarrasine de Tortosa et, de manière générale, les musulmans du delta de l'Ebre et de la Ribera, ont été étudiés par J. Font Rius au moment de la conquête chrétienne, et, pour le XIII ${ }^{e}$ siécle, par Roser Argemí dans un mémoire de licence resté, mal- 
heureusement, inédit. Je suis moi-même en train d'étudier l'aljama de Tortosa au XIVe siécle. D'autres publications très ponctuelles, ou bien des œuvres générales, mentionnent également cette aljama ${ }^{18}$.

\section{Aragon}

Les synthèses à consulter sur les mudéjars d'Aragon, outre les auvres générales déjà citées, sont celles de F. Macho y Ortega, dotées d'une bonne collection de documents, et bien qu'anciennes, encore fondamentales ${ }^{19}$, celle de J. M. Lacarra ${ }^{20}$, le chapitre que leur consacre M.-L. Ledesma dans l'Histoire d'Aragon et un état de la question du même auteur, daté de 1988'21. Qui s'intéresse à la peu abondante documentation interne des mudéjars aragonais trouvera un état complet de la question dans un travail de M. J. Viguera'22.

La source unique d'information, pour connaître même de manière approximative le nombre des musulmans habitant en Aragon, est le recensement de 1495. Selon ce censo, le total des feux du royaume s'élevait à 51540 , tandis que les feux moros étaient de 5674, soit $10 \%$ du total de la population ${ }^{23}$.

Pourtant, les historiens spécialisés dans l'histoire des morisques, par exemple Gregorio Colás, mettent en doute la fiabilité de ce censo, car les différences très importantes observées avec les recensements postérieurs, qui ne peuvent être imputées à la croissance végétative, mettent en évidence qu'il y a eu occultation de feux. Ce soupçon est confirmé par des études au niveau local, qui montrent qu'au bout de quelques années le nombre des feux musulmans était le double, ou plus, de celui indiqué dans le censo de 1495. Selon celui-ci, Illueca comptait 39 feux musulmans, alors qu'un décompte de 1526 en fait apparaitre 78. A Calanda, il y en avait 116, selon le censo, et 240 en 1514. Cela amène G. Colás à supposer qu'en réalité la population musulmane, ou morisque, représentait un pourcentage supérieur, de 15 a $20 \%$ du total. Mais il faut ajouter que l'occultation des feux ne concerna pas seulement la population islamique, mais également les chrétiens. Le même G. Colás note que le censo de 1495 indique seulement trois feux chrétiens à Calanda, alors qu'en 1514 il en apparaît 1424. La seule conclusion valable est que 5674 feux représentent le minimum d'une population musulmane qui constituait au moins $10 \%$ des habitants de l'Aragon.

La majorité de la population musulmane restée en Aragon se trouvait concentrée dans la vallée de l'Ebre et sur le cours moyen et inférieur de ses affluents de droite, dans une zone agricole riche $^{25}$. Plus au Nord, Huesca comptait une morería importante et une population musulmane dispersée sur le territoire proche ${ }^{26}$. Sur la limite avec la Catalogne, Mequinenza et Fraga, cette dernière ville ayant appartenu au Principat jusqu' au XVe siècle, possédèrent des morerias importantes. D'autres noyaux de peuplement musulman se trouvaient situés sur les rives du Cinca, affluent de gauche de l'Ebre, ou à proximité : Bellver, Alcoleja, Albalat, Binacet, Monzón, Sant Esteve de Llitera, Tamarit de Llitera, Barbastro et Naval.

La région de Teruel n'avait de population mudéjare que dans la ville elle-même et dans la zone de l'Albarracín, bien qu'il semble que cette population n'ait pas été originaire du pays, vidé de peuplement islamique après la conquête chrétienne, sûrement pour des raisons stratégiques, puisqu'il s'agissait d'une zone frontalière du royaume de Valence, qui se trouvait encore au pouvoir des musulmans. Plus tard, on y établit des mudéjars provenant d'autres zones et d'anciens captifs, dans des secteurs déterminés, afin de renforcer son économie ${ }^{27}$.

En ce qui concerne les établissements de la vallée de l'Ebre et de ses affluents, on sait que, près de la frontière navarraise et castillane, dans la vallée du Queiles, affluent de l'Ebre, il existait une morería importante à Tarazona, tandis que Novallas, Malón, Vierlas, Tortoles, Cunchillos, Torrellas, Santa Cruz, Grisel, Samangos et, jusqu'au XIV siécle, Los Fayos, constituaient des localités habi- 
tées uniquement par des mudéjars. Dans la vallée voisine du Huecha, Borja, Bulbuente, Ambel, Trasmoz et Magallón possédaient des morerías, tandis que Fréscano, Agón, Bisimbre, Albeta, Bureta, Maleján, Ribas et, jusqu'au Xıve siécle, Vera et Alcalá, étaient de peuplement mudéjar. Les études portant sur Tarazona et Borja, comme celles concernant le monastère voisin de Venuela donnent de nombreux renseignements sur les mudéjars ${ }^{28}$.

Dans la vallée du Jalón les localités habitées par des mudéjars, ou possédant des morerias importantes, étaient également nombreuses, telle Calatayud. Il faut citer également Moros, Terrer, Paracuellos, Saviñán, Morés, Morata, Arándiga, Illueca, Gotor, Mesones, Ricla, Calatorao, Lucena, Epila, Lumpiaque, Rueda, Plasencia de Jalón, etc ${ }^{29}$. Dans la vallée de son affluent, le Jiloca, Daroca possédait une morería très importante, de même que Báguena, Burbáguena, Murero et Villafeliche ${ }^{30}$.

Entre les vallées du Jalón et du Huerva, quelques villages de culture sèche comptaient également, par exception, un peuplement mudéjar, par exemple Alfamén, Almonacid de la Sierra et Longares. Dans la vallée du Huerva on peut mentionner Villanueva del Huerva, Muel - fameuse par sa poterie -, Botorrita, María, Cadrete, Novells et Cuarte. L'Ordre de l'Hôpital possédait d'importants domaines dans cette zone ${ }^{31}$. Dans la vallée de l'Aguas les lieux possédant la population mudéjare la plus importante étaient Letux, Belchite et $\operatorname{Codos}^{32}$, tandis que sur la rivière Martín il s'agissait d'Híjar et de Samper de Calanda, et, sur le Guadalope, de Calanda; l'Ordre de Calatrava dominait dans cette dernière zone ${ }^{33}$.

Nous n'avons pas mentionné les localités de la vallée même de l'Ebre, qui comptaient des morerías importantes comme Pedrola, Alcalá, Alagón, Saragosse naturellement, Fuentes de Ebro, Pina, Sástago, Escatrón et Caspe ${ }^{34}$.

Le catalogue que nous préparons de la documentation concernant les mudéjars aragonais contenue dans les registres de chancellerie des Archives de la Couronne d'Aragon permettra d'améliorer la connaissance des établissements, de l'organisation et des activités de ces mudéjars. Un premier volume, contenant la documentation du règne de Jacques II (1292-1327), se trouve dans une phase d'élaboration très avancée et j'espère qu'il pourra être publié en $1992^{35}$.

\section{Le royaume de Valence}

La situation des mudéjars valenciens après la conquête du royaume de Valence, au XIIr siécle, est maintenant bien connue, dans la mesure de ce que permet la documentation conservée, grâce au travail extraordinaire réalisé par le $\mathrm{P}$. Burns ${ }^{36}$. Traditionnellement, le XVe siécle était doté, dans cette région, d'une bibliographie plus abondante, due à Gual Camarena, Piles Ros, Roca Traver ${ }^{37}$, entre autres, auxquels se sont ajoutés récemment C. Barceló, D. Bramon, M. Meyerson, etc. ${ }^{38}$ Pour cette raison, avec les collègues qui travaillent avec moi, nous avons centré notre étude sur le XIVe siécle dans tout le royaume de Valence, mais particulièrement sa zone méridionale ${ }^{39}$. Notre fichier, provenant du dépouillement systématique des registres de chancellerie des Archives de la Couronne d'Aragon, nous permettra d'entroprendre en outre, si nous obtenons les moyens nécessaires, la publication d'un catalogue analogue à celui qui va bientôt être publié pour l'Aragon.

Il reste à ajouter que, dans les domaines de la toponymie et de l'onomastique, C. Barceló et $\mathrm{A}$. Labarta ont réalisé des apports fondamentaux pour les historiens et les philologues, de même que M. de Epalza et M. J. Rubiera. Les deux premières ont fait connaître, en outre, de la documentation arabe interne des musulmans valenciens ${ }^{40}$.

On calcule qu'au milieu du XVe siécle la population totale du royaume de Valence dépassait légèrement les 250000 habitants, dont les musulmans représentaient environ les $30 \%$. Parmi les territoires constituant la Couronne d'Aragon, c'était celui qui comptait la proportion la plus élevée de population islamique, avec la particularité que la situation frontalière du royaume fai- 
sait de cette population un danger potentiel pour sa sécurité.

En parcourant le pays valencien du nord au sud, on observe que les cantons les plus septentrionaux, le Maestrazgo et les Ports de Morella, de même que la façade maritime, dans l'actuelle province de Castellón, ne possédait pas de population musulmane, à l'exception de quelques localités situées sur la limite du Maestrazgo, comme Culla ou Alcalá de Xivert. Il n'y avait donc pas continuité avec les établissements islamiques du delta de l'Ebre, en Catalogne. La plaine littorale autour de Castellón avait bien des localités de peuplement mixte comme le chef-lieu lui-même, Oropesa, Borriol, Borriana, la Vila-real et le Vall d'Uixó, habité en majorité par des sarrasins, mais la concentration la plus forte se trouvait dans les vallées intérieures des rivières Millars et Palancia, de même que dans la Serra d'Espadá, dans des lieux tels que Fanzara, Toga, Cirat, Aranyuel, Suera, Benitandús, Veo, Aín, Eslida, Artana, Onda, Tales, Fondeguilla, Castre, Xóvar, Assuévar, Almedíxer, Almonesir, Segorbe, Altura, etc ${ }^{42}$.

Sur la côte, en se dirigeant vers Valence, la vallée de Sego était également de peuplement islamique et Sagonte, appelée au Moyen Age Morvedre, possédait une morería. La Horta de Valence avait également conservé des habitants musulmans, aussi bien le chef-lieu, avec une morería importante, comme la huerta, ò se détachaient Manises et Paterna, pour leurs potiers, Mislata, Quart, Alaquás, Picassent, Torrent, etc ${ }^{43}$.

Un peu plus à l'intérieur, en remontant la vallée du Turia, ou à proximité, Riba-roja, Vilamarxant, Benaguasil, La Pobla de Vallbona, Bétera, Llíria, Xestalgar, Xulella et la vallée de Xelva comptaient également une population mixte, ou totalement musulmane.

Dans la zone comprise entre les vallées du Turia et du Xúquer (castillan Júcar), dans le canton appelé Foia de Bunyol, une population musulmane est attestée à Bunyol, Dosaigües, Xest, Xiva etc., et cette population était également nombreuse sur le cours moyen du Xúquer et dans les cantons voisins, où Xătiva possédait la morería la plus nombreuse du royaume de Valence. D'autres localités de peuplement mixte, ou intégralement musulman, étaient constituées par Torís, Montserrat, Alfarb, Carlet, Alzira, Massalavés, Alberic, Cotes, Antella - lieu d'origine de Cilim, le pseudo-prophète qui dirigea une révolte en 1359 -, Tous, Cárcer Bicorb, Quesa, Navarrés, Bolbait, Xella, Anna, Canals, Moixent, et toute la vallée d'Aiora"'.

Plus au Sud, les vallées d'Albaida et de Seta, et les cantons de Cocentaina et d'Alcoi, celui de la Safor, sur le littoral, avec la vallée d'Alfándec ou de Valldigna, Gandía, Beniopa etc. constituaient une région de peuplement islamique très dense ${ }^{45}$, que dépassait seulement, de ce point de vue, la zone de la Muntanya, correspondant aux actuels cantons de la Marina Alta et de la Marina Baixa. Dans cette zone, à Atzeneta, aujourd'hui sur la commune de Benifato, dans la vallée du Guadalest, se trouvait la tombe d'un membre de la famille Sid Buna, considéré comme un saint, constituant le sanctuaire islamique le plus vénéré de toute la Couronne catalano-aragonaise. Les vallées de Laguar et de Gallinera appartenaient également à cette zone ${ }^{46}$.

A l'extrémité méridionale, les cantons d'Alacant (Alicante), Elx (Elche), Crevillent, la vallée d'Elda et Novelda et la zone d'Oriola (Orihuela) furent rattachés au royaume de Valence par suite de la guerre avec la Castille en 1296-1304 et de la division de l'ancien royaume de Murcie entre les belligérants. Cette région également était intensément peuplée de sarrasins, en particulier la vallée du Vinalopó : Elx, Crevillent, la vallée d'Elda et Novelda. Crevillent fut précisément la dernière seigneurie musulmane, avec un statut analogue à celui d'une seigneurie chrétienne, dans les premières décennies du XIV' siècle ${ }^{47}$. 


\section{Organisation interne}

Il est bien connu que les muđéjars, ou "Sarrasins", s'organisèrent en aljamas, analogues aux municipalités chrétiennes. Leur fonctionnement était basé sur les personnes de l'alamín, dirigeant la communauté et nommé par le seigneur, des "jurés" (jurados) ou "anciens" (viejos), le cadi, rendant la justice, et le zalmedina, s'occupant des affaires mineures et qui, dans les petites communautés, était le seul officier. L'alfaqui s'occupait du culte. Dans les aljamas importantes, un clavaire gérait les comptes. La plus grande part de la bibliographie citée traite de l'organisation des aljamas.

Du fait des accords signés au moment de la conquête, ces communautés s'administraient selon leur propre loi, "par suna et xara", aspect que les derniers apports bibliographiques permettent de mieux connaître ${ }^{48}$. Les appels, ainsi que la surveillance du système judiciaire, revenaient à l'alcadi general, nommé par le ro ${ }^{49}$. Pourtant certaines affaires revenaient au batlle ou au merino : celles où intervenait un chrétien, ou bien de caractère criminel. Le roi réclamait pour son tribunal les affaires dites de "plagi o collera", à savoir le rapt de chrétiens libres en vue de leur transport en terre islamique, la collaboration avec les bandits grenadins, etc ${ }^{50}$.

\section{Les activités économiques}

La majeure partie de la population islamique des trois royaumes se consacrait à l'agriculture, parfois comme propriétaire de la terre, parfois comme locataire. Dans ce cas, il fallait remettre au seigneur une partie de la récolte oscillant entre le tiers et le quart sur les terres irrigúess, entre le cinquième et le septième pour les cultures sèches. Le seigneur pouvait exiger également des prestations personnelles, comme les corvées (sofras), la remise d'aliments, ceufs, volailles, fourrage ou paille etc. Dans certaines zones l'exploitation des friches, terres salés et marécageuses, où l'on récoltait la cochenille pour la fabrication des teintures, le sparte et le jonc pour la vannerie et la natterie, et les herbes à soude pour l'obtention de ce produit', avait son importance.

Les mudéjars pratiquaient également une grande variété de métiers artisanaux, mais ils se distinguaient dans ceux de la construction, aussi bien dans l'élaboration des matériaux : briques, dalles, plâtre, bois etc., que dans la construction elle-même ${ }^{52}$. Ils dominaient dans la poterie, les cuirs, la vannerie du sparte et du jonc, le filage et le tissage de la soie. Ils se distinguaient dans la fabrication des armes, dans l'élaboration du savon. Ils possédaient le monopole de la fabrication du papier à Xàtiva. Ils jouaient un rôle très important dans les transports, avec les convois de mules ainsi que dans le transport fluvial sur l'Ebre ${ }^{53}$. Parmi eux les marchands n'étaient pas absents, même du grand commerce international avec la Castille et le Nord de l'Afrique ${ }^{54}$. Les médecins ne manquaient pas non plus ${ }^{55}$.

\section{La ségrégation}

L'Eglise exigeait la ségrégation dans la résidence, comme sauvegarde de la foi des chrétiens, mais les musulmans aussi souhaitaient demeurer à part, pour la même raison. Aussi, dans les villes et localités où une partie de la population musulmane se maintint après la conquête chrétienne, elle dut se loger dans des quartiers périphériques.

Mais la ségrégation fut difficile à observer à l'intérieur des morerías, où beaucoup de convertis demeuraient après leur baptême, et où s' installait une population de marginaux, prostituées et autres. 
Les musulmans de passage devaient se loger dans des auberges (alfondacs) qui leur étaient réservées. Il était interdit que les chrétiens, en particulier les convertis, se mêlent aux moros dans des fêtes et des cérémonies. La fréquentation en commun des tavernes, les musulmans valenciens buvant en abondance, était également prohibée, bien que cette règle fût habituellement transgressée.

Naturellement le mariage, comme tout autre type de relation amoureuse, était interdit entre chrétiens et musulmans. Pourtant une abondante documentation prouve que les transgressions étaient fréquentes, en particulier la relation entre chrétien et musulmane, car celle entre musulman et chrétienne était punie beaucoup plus sévèrement, avec le bôcher pour le moro, tandis que dans l'autre cas la femme musulmane ne s'exposait qu'à l'esclavage. Il existe une riche casuistique sur le sujet : erreurs judiciaires, destin des enfants issus d'unions mixtes, mariages avec l'un des époux converti etc.

Le respect de la ségrégation exigeait que les mudéjars se distinguent extérieurement des chrétiens, mais cela devenait difficile au XIV siecle, parce que les hommes au moins avaient abandonné leurs vêtements caractéristiques et leur allure ne se distinguait pas de celle des chrétiens. Aussi leur imposa-t-on une coupe de cheveux et de barbe spéciale et, dès la fin du XIV' siécle, une marque sur le vêtement, mesure qui se heurta à une grande résistancest.

\section{La pratique religieuse et le prosélytisme}

Les convertis de l'islam au christianisme furent beaucoup plus nombreux que l'on ne le croyait, en particulier dans les villes, du fait du contact et du prosélytisme chrétien. La conversion posait de nombreux problèmes : conservation des biens, dissolution ou continuité de la famille du converti, relations avec les musulmans et les chrétiens, etc ${ }^{77}$. Parfois les convertis revenaient à la religion musulmane. Les procès étudiés par M. L. Ledesma contre des musulmans relaps sont du plus haut intérêt à cet égard ${ }^{38}$.

Malgré l'engagement de respecter la religion musulmane contracté par les chrétiens au moment de la conquête, il y eut des restrictions concernant l'entretien de certaines mosquées, particulièrement des minarets, et les musulmans se plaignirent fréquemment de viols et de pillages de tombes dans leurs cimetières. La pression de l'Eglise imposa des dispositions contre l'appel à la prière musulmane, la "salal", et des restrictions à la célébration des pèlerinages, en particulier au sanctuaire d'Atzeneta, et au travail des musulmans les jours de fête chrétiens.

\section{La liberté de circulation et l'émigration}

La circulation intérieure des mudéjars n'était limitée que par l'obligation, dans le royaume de Valence, d'emprunter les chemins royaux. Dans le gouvemorat d'Orihuela les restrictions furent plus grandes, du fait de la proximité de la frontière de Grenade. La liberté de changer de lieu de résidence était en principe totale, mais elle se voyait limitée dans la pratique tant par les engagements de résidence contractés par les moros que par les arguties utilisées par les seigneurs pour retenir leurs "vassaux" musulmans. A la fin du XIV' siécle on tenta d'accrôtre les entraves aux migrations intérieures.

Les voyages à l'extérieur, pour raisons commerciales ou familiales, ou pour effectuer le pèlerinage à La Mecque, étaient permis, mais nécessitaient une autorisation de sortie du royaume, et des cautions.

La liberté d'émigrer, reconnue en principe dans les chartes de peuplement et dans les privilèges accordés aux mudéjars, se vit soumise à de nombreuses restrictions au long du XIve siécle jusqu'à 
être interdite en 1403 dans le royaume de Valence. L'attitude de la Couronne consista en général à permettre l'émigration, parce que c'était là un engagement contracté par elle, et aussi parce qu'elle fournissait des revenus importants : le dixième de tous les biens que l'émigrant emmenait avec lui, outre d'autres impôts. Les guerres entrainèrent parfois l'arrêt temporaire de l'émigration. D'autres suspensions de celle-ci furent dues à la pression de la noblesse, qui obtint finalement en 1403 qu'on interdît l'émigration mudéjare du royaume de Valence. Il faut noter que les pressions nobiliaires en ce sens commencèrent avant la chute démographique provoquée par la Peste Noire de 1348 et par la guerre avec la Castille de 1356-1366. Le montant de l'impôt de sortie et les dangers affrontés par les émigrants, poursuivis sur terre et sur mer par des bandits et des pirates, incitaient beaucoup de mudéjars à tenter l'émigration clandestine.

Malgré les avantages possibles de la vie dans un pays islamique, beaucoup d'émigrants ne parvenaient pas à s'acclimater à une nouvelle société et revenaient à leurs lieux d'origine en terre chrétienne. Il leur fallait pour cela une autorisation spéciale, à défaut de quoi ils risquaient l'esclavage. L'intérêt de maintenir et d'accroôtre la population mudéjare établie en terre chrétienne donna même lieu à quelques essais d'attraction d'immigrants à Grenade et dans le Nord de l'Afrique ${ }^{59}$.

\section{La cinquième colonne}

Bien que l'attitude de méfiance à l'égard de la communauté musulmane, considérée comme une cinquième colonne des pays islamiques ennemis, se soit rencontrée sporadiquement en Catalogne, particulièrement à Tortosa, et à l'occasion également dans le Bas Aragon, le phénomène fut surtout continuellement présent dans le pays valencien, à cause de la proximité de la frontière terrestre avec Grenade et de l'existence d'une longue côte, ouverte aux attaques des flottes musulmanes, de Grenade ou du Nord de l'Afrique, cette côte constituant une véritable frontière maritime.

Bien qu'on ait eu tendance récemment à minimiser l'importance de la communauté mudéjare comme cinquième colonne de l'ennemi islamique extérieur, la documentation chrétienne se voit corroborée sur ce point par celle d'origine islamique, tel un très intéressant pamphlet incitant à la rébellion, rédigé à Barcelone, durant le règne de Yusuf III de Grenade (1408-1417) ${ }^{60}$.

Pour cette raison, les chrétiens prirent, en cas de danger, des otages, femmes et enfants, aux mudéjars, contrôlèrent les armes qu'ils possédaient, leur interdirent l'accès des châteaux, sauf dans des circonstances très particulières et moyennant la remise préalable d'otages etc. En certaines occasions des accusations précises furent portées contre des mudéjars, d'entretenir des contacts avec le Maroc ou avec Grenade, dans le but de faire coïncider une révolte avec une attaque de la part de ces états. Les agitations des mudéjars valenciens en 1304, 1331 et 1340, ou celle du prophète Cilim en 1360, n'allèrent pas jusqu'à la révolte armée, bien que dans ce dernier cas le mouvement ait coïncidé avec une attitude peu loyale de la part de certaines aljamas musulmanes de Valence dans la guerre avec la Castille. En 1304 il est avéré que des groupes de mudéjars s'unirent à l'armée de Grenade dans une incursion de celle-ci à travers le pays valencien. Des centaines de mudéjars l'accompagnèrent dans sa retraite : de 1000 à 2000 personnes abandonnèrent ainsi la zone située entre Alcoi, Denia et la frontière (castillane). La fuite massive se répéta en 1331 et 1332, à l'occasion d'autres incursions grenadines.

Selon les chrétiens, les mudéjars, en particulier les plus proches de la frontière murcienne, collaboraient également avec les almogávares et bandits grenadins dans leurs incursions pour voler du bétail ou enlever des gens sur les terres de Valence, afin de les vendre à Grenade. Les almogávares chrétiens répondaient à ses incursions en procédant de manière semblable et prenaient en outre 
des captifs dans les communautés mudéjares. La confusion en résultant fut telle que s'imposa l'organisation d'une "Fraternite" (germandat) des aljamas musulmanes et des municipalités chrétiennes, qui s'engagèrent à agir solidairement avec l'autre communauté dans la recherche des disparus, le paiement des rançons et l'indemnisation pour les morts ${ }^{61}$.

\section{NOTES}

1. Pour plus de concision dans les rtffrences, nous utiliserons les abreviations suivantes: "AA"= "Al-Andalus" ; "AUA.HM"= "Anales de la Universidad de Alicante. Historla Medieval"; "AFM.EES" = "Aragon en la Edad Media. Estudios de Economía y Sociedad" ; "AHR"= American Historical Review"; "AQ"= "Al Qantara" ; "B"= "Barcelona" ; "BSCC"= "Boletfn de la Sociedad Castellonense de Cultura" ; "CSIC" = "Consejo Superior de Investigaciones Clentfficas" ; "EEMCA" = "Estudios de Edad Media de la Corona de Aragon" ; "IEA"= "Instituto de Estudios Alicantinos" ; "IEC"= "Instiut d'Estudis Catalans"; "IMF"= "Instluci6 Mila i Fontanals" ; "IEI"= "Institut d'Estudis Ilerdencs" ; "IET"= "Institut d'Estudis Tarraconenses Ramon Berenguer IV" ; "IETur"= "Instibuto de Estudios Turolenses" ; "TFC"= "Institución Fernando el Católico"; ; "L"= "Leida" [LÉida] ; "M"= "Madrid" ; "PM" = "Palma de Mallorca" [Palma de Majorque] ; "SAA"= "Sharq at-Andalus" ; "SIM"= "Simposio Internacional de Mudejarismo"; "T"= "Tarragona" [Tarragone] ; "Val" = "Valencia" [Valence] ; "Z" = "Zaragoza" [Saragosse].

2. M.-J. Viguera, Aragón musulman, Z, 1981, offire une vision claire de la domination islamique dans cette région jusqu'à la victoire chrettienne et au repli musulman. Cf., pour la domination musulmane à Lérlda, R. Pita Mexce, Lérida arabe, $L$, Dilagro, 1974, 172 p., et une synthese de la domination musulmane et de l'avance territoriale chretienne en Catalogne dans L. M. Salrach, História dels Palisos Catalans, dels origens a I714, A. Balcells Éd., I, B, Edhasa, 1980, p. 149-294. Cf. egalement R. d'Abadal i de Vinyals, Catalunya carolingia, I. El domini carolingi a Catalunya, J. Sobreques i Callico6 6d., Premiere partie, IEC, B, 1986, et P. Balañà i Abadia, Els musulmans a Catalunya (713-1153). Una aproximació bibliogradfica, tired-part de "SAA", 3 (1986), 47 p.

3. J.-M. Lacarra, Documentos para el estudio de la reconquista y repoblación del valle del Ebro, EEMCA 2(1946), p. 469 574 ; 3 (1947-1948), p. 499-727 ; 5 (1952), p. 511-668 ; r6́d. en livre, avec index de M. T. Iranzo Mữío et J. Sánchez Usòn, Z, Anubar, 1982-1985, 2 vol.

4. J. M. Font i Rius, Cartas de población y franquicia de Catalufa, CSIC, M-B, 1969 et 1983, 3 vol.

5. Cf. une synthèse récente de la période islamique, de la reconquête, du repeuplement etc. dans P. Cateura, Ampliacio de la Corona d'Arago, I. El regne de Mallorca, dans La Corona de Aragón, 4, Z, 1989, p. 102-140 (6d. bilingue). Egalement R. Soto i Company, Repartiment $i$ repartiments : l'ordenacio d'un espai de colonitzacio feudal a la Mallorca del segle XIII, dans De al-Andalus a la sociedad feudal : los repartimientos bajomedievales, CSIC, IMF, B, 1990, p. 1-52. Sur les musulmans des îles, cf. H. Lourie, Free Moslems in the Balearics under Christian Rule in the Thirteenth Century, "Speculum", 45 (1970), p. 624-649; N. E. Gais, Aperçu sur la population musulmane de Majorque au XIV" siècle, "Revue d'Histoire et de Civilisation du Maghreb", 9 (1970), p. 19-30 ; R. Soto, La población musulmana de Mallorca bajo dominio cristiano, "Fontes Rerum Balearium" (PM, 1978), p. 65-80 et (1979-1980), p. 549-564, et Sobre mudèixars a Mallorca fins a finals del s. XIII, dans Estudis de Prehistoria, d'Historia de Mayurqa i d'Histdria de Mallorca dedicats a Guillem Rossello Bordoy, PM, 1982, p. 195-221 ; J. Sastre Moll, Notas sobre la poblacion musulmana de Menorca (1287), dans Les Illes orientales d'Al-Andalus, IEB, PM, 1987, p. 145-161. Egalement F. Franco Sánchez, Bibliografia sobre temas drabes de las Baleares, "SAA", 3 (1986), supplément bibliographique, 44 p. En particulier, A. Santamaría, Ejecutoria del reino de Mallorca, Ajuntament de Palma, PM, 1990, 646 p.

6. Sur l'époque musulmane du royaume de Valence et la conquête par Jacques $1^{\circ}$, M. Sanchis i Guarner, Epoca musulmana, dans Historia del País Valencia, I, B, Edicions 62, 1965, p. 207-370, réimprimé en 1989, p. 227-394, et les syntheses plus récentes de P. Guichard, La Valencia musulmana et La conquista militar y la estructuración del reino, dans Nuestra Historia, Val, Mas Ivars, 1980, t. 2, p. 201-280 (en collaboration avec A. Bazzana, p. 263-280), et t. 3, p. 13-107, et de P. Lopez Elum, La conquesta et $L$ a repoblació valenciana, dans Història del País Valencià, II. De la conquesta a la federací6 hispanica, B, Ed. 62, p. 57-112. Egalement M. Gual Camarena, Las cartas pueblas del reino de Valencia, éd. préparée par D. PÉrez PErez, “750 Aniversari 1238-1989", Generalitat Valenclana, Val, 1989, 212 p. (Noter qu' il ne s' agit que des régestes des documents). Sur le dernier mi de Valence islamique et sa descendance chrétienne, E. Molina López, Ceyt Abu Ceyt : novedades y rectificaciones, Almeria, 1977 ; C. Barceló Torres, El sayyid Abu Zayd : principe musulmán, señor cristiano, "Awraq", III (1980), p. 101-109 ; R. Burns, Principe almohade y converso mudejar : nueva documentación sobre 
Abu Zayd, "SAA", 4 (1987), p. 109-122 ; Regalo para una madre : una muchacha esclava musulmana del nieto de Abu Zayd, el señor de Borriol (130I), ibid. 6(1989), p. 115-117.

7. F. de Momblanch y Gonzálbez, El rey D. Jaime y las guerras de Alazrach, VII Asamblea de cronistas de Valencia (1968), Val, 1970 ; Al Azrag, capitan de moros. Aportación a la historia del reino de Valencia en el siglo XIII, Obra cultural de la Caja de Ahorros de Alicante y Murcia, Val, 1977 ; D. Bramon, La reconquesta valenciana i els origens del problema morisc, "Arguments", 3 (Val, L'Estel, 1977), p. 49-62 ; R. Baño Arminyana, Contribució a l' estudi de les sublevacions d'Al-Azraq en les comarques de l'Alcoid i del Comfat, "Revista de Investigación y Ensayos del IEA", XXXIII (1981), p. $39-63$; R. I. Bums et P. E. Chevedden, El tractat de rendició d'Al-Azraq amb Jaume II i l'infant Alfons en 1245 : el text àrab i el context valencid, dans Homenatge al Prof. Manuel Sanchis Guarner (1911-1981), "L'Espill", 17-18 (1983), p. 231257 ; version anglaise dans "Der Islam", 66 (1989), p. 1-37 ; R. I. Bums, La guerra de Al-Azraq de 1249, "SAA", 4 (1987), p. 253-256; A lost Crusade : Unpublished Bulls of Innocent IV of al-Azraq's rewolt in 13th. Century Spain, "Catholical Historical review", LXXIV (1988); The Crusade against al-Azraq : a thirteenth-century mudejar revolt in international perspective, "AHR", 93 (1988), p. 80-106.

8. R. I. Burns, Los mudéjares de la Valencia de las Cruzadas: un capítulo olvidado de la historia islámica "SAA", 1 (1984), p. 15-34 (Trad. de Les mudéjars du royaume de Valence : une majorité traitée en minorité, dans Minorités et marginaux en France méridionale et dans la Péninsule lberique (vir-xVIr siécles), Paris, CNRS, 1986, p. 95-118).

9. Pour les ouvrages, M. T. Ferrer i Mallol, Els sarraüns de la Corona catalano-aragonesa en el segle XIV. Segregacio $i$ Discriminaci6, CSIC, MMF, B, 1987, 427 p. ; La frontera amb l'Islam en el segle XIV. Cristians $i$ sarrains al Pais Valencid, CSIC, MF, B, 1988, 533 p. ; Les aljames sarraïnes de la governació d'Oriola en el segle XIV, CSIC, IMF, B, 1988, 338 p. ; La frontera terrestre i maritima amb l'Islam, "Miscell lània de Textos Medievals", 4, CSIC, IMF, B, 1988, 333 p.; Organitzacio i defensa d'un territori fronterer. La governacio d'Oriola en el segle XIV, CSIC, IMF, B, 1990, 631 p. ; M. B. Basaniez Villaluenga, La aljama sarracena de Huesca en el siglo XIV, CSIC, IMF, B, 1989, 275 p. Pour les articles, La carta de població dels sarrains de la Vall d'Aiora (1328), "SAA", 3 (1986), p. 81 -94; La batlia general de la part del regne de València delld Xixona (s. XIV), "AUA.HM", 6 (1987), p. 279-309 ; Toponímia medieval d'Oriola, Miscell lània d'Homenatge a Enric Moreu Rey, Abbaye de Montserrat, II, B, 1988, p. 195-211 ; La frontera meridional valenciana durant la guerra amb Castella dita dels dos Peres, dans Pere el Cerimonios i la seva època, CSIC, IMF, B, 1989, p. 245-357; Un procés per homicidi entre sarrains de l'horta d'Alacant (1315), "SAA", 7 (1990), p. 135-150. Dans Homenatge a la memoria del Prof. Emilio SGez (1917-1988). Aplec d'estudis dels seus deixebles i col.laboradors, Université de Barcelone, Centre d'Estudis Medievals de Catalunya Pere III, CSIC, MF, B, 1989, cf. les articles suivants : M. T. Ferrer i Mallol, Notes sobre la conquesta del regne de Múrcia per Jaume II (1296-1304), p. 27-44 ; L. M. Jimeno Ontuño, Notas hist6ricas sobre la aljama sarracena de Daroca durante el último tercio del s. XIII, p. 213-221; R. Mayordomo Font, Notas históricas sobre la carnicerfa de la aljama sarracena de Tortosa (siglo XIV), p. 223-231 ; M. B. Basañez Villaluenga, Jurisdicción de la aljama sarracena de Huesca (siglo XIV), p. 233-242. En 1992 paraîtra le livre de J. Mutgé sur l'aljama sarrasine de Lérida et un volume du Catálogo de documentos sobre los sarracenos de Aragón (reinado de Jaime II). Une thèse sur la délinguance chez les Sarrasins de la Couronne d'Aragon au XIVe siècle est en cours d'élaboration. Je n'ai pas inclus les travaux ni les thises sur les rapports avec les pays islamiques, la course, les captifs etc.

10. J. Boswell, The Royal Treasure : muslim communities under the Crown of Aragon in the Fourteenth century, New HavenLondres, Yale UP, 1977, 522 p.

11. M. T. Ferrer i Mallol, Els sarraïns de la Corona catalano-aragonesa en el segle XIV. Segregació i discriminaci6, cf. note 9.

12. W. Küchler, Bestewerung des Juden und Mauren in den Ländern der Krone Aragons während des IS Jahrhunderts, Spanische Forschungen der Görresgesellschaft, "Gesammelte Aufsătze zur Kulturgeschichte Spaniens", XXIV (1968), p. 227-256.

13. M. García-Arenal, Los mudéjares en el reino de Navarra y en la Corona de Aragón. Estado actual de su estudio, III SIM (Teruel, 1984), Actas, Teruel, IETur, 1986, p. 175-186.

14. J. Vemet, Antropónimos de etimología arabe en el Levante español : ensayo metodológico, "Revista del Instituto de Estudios Islámicos en Madrid", XI-XII (1963-1964) ; Antropónimos árabes conservados en apellidos del Levante Español, "Oriens", XVI (1963) ; Antroponimos musulmanes en los actuales partidos judiciales de Falset y Gandesa, tous rédités dans "SAA", 5 (1988), p. 203-220, et dans De Abd al-Rahman I a Isabel II (Recopilación de estudios dispersos sobre Historia de la ciencia y de la culura española ofrecida al autor por sus discípulos con ocasión de su LXV aniversario), B, 1989.

15. J. Iglésies, L'empadronament moro a Catalunya als anys 1496 i 1515, Miscell lània d'Homenatge a Enric Moreu-Rey, II, Abbaye de Montserrat, B, 1988, p. 269-286. Le fogatge inclut la liste des titulaires de chaque feu. Sur le même sujet, cf. également : A. Masiá, Los moros residentes en Cataluña según los fogatges de 1491, 1497 y I515, "Tamuda", 3 (1955), p. 282-300.

16. P. Sanahuja, OFM, Lerida en sus luchas por la fe (judios, moros, conversos, inquisición y moriscos), IEI-CSIC, L, 1946; J. M. Font Rius, La reconquista de Lérida y su proyección en el orden juridico, "Ilerda", VIII (1949), p. 5-31, réd. dans Estudis sobre els drets $i$ institucions locals en la Catalunya medieval, p. 55-92 ; J. Lladonosa, Història de Lleida, Tarrega, Ed. Camps Calmet, 1972-1974, 2 vol. ; R. Pita Merce, Lérida morisca, L, Dilagro, 1977, 200 p. 
17. J. M. Font I Rius, La carta de seguridad de Ramón Berenguer $N$ a las morerias de Ascó y Ribera de Ebro (siglo XII), Homenaje a D. José Marfa Lacarra de Miguel en su jubilación del profesorado, I, Z, 1977, p. 261-283, rét. dans Estudis sobre els drets $i$ institucions locals en la Catalunya medieval, B, Ed. de l'Université de Barcelone, 1985, p. 561-576 ; C. Biarnés i Biarnés, Moros i moriscos a la Ribera de l'Ebre (710-1615), B, R. Dalmau 6d., 1972, 66 p. (Episodis de la Història, 163) ; Els moriscos a Catalunya, Asco, 1981 ; Convivencia de moros y cristianos en Ascó, Actas del II Congreso internacional de las Tres Culturas, Tolede, 1985 ; P. Ortega Pérez, Alguns aspectes de la repoblació de Miravet (Ribera d'Ebre) després de l'expulsí́ dels moriscos (1610-1623), "Pedralbes. Revista d'Historia Moderna", 6 (1986), p. 39-70 ; De mudejares a moriscos; algunas reflexiones en tomo a las relaciones sociales de producción y la conflictividad religiosa : el caso de la Ribera d'Ebre (Tarragona), "Miscell lània de Textos Medievals", 4. La frontera terrestre i marítima amb l'Islam, CSIC, IMF, B, 1988, p. 319-333 ; La orden de San Juan de Jerusalén y Miravet (primera mitad del s. XVII), IET, T, 1988, 266 p. ; Els Hospitalers a la Ribera d'Ebre. Benissanet, ss. XVI-XVII, Diputaci6 de T, 1990, 92 p. En ce qui concerne la baronnie d'Entença, cf. M. Romero Tallafigo, El señorfo catalán de los Entenza a la luz de la documentación existente en el Archivo Ducal de Medinaceli (Sevilla), "Historia. Instifuciones. Documentos", 4 (1977), p. 515-582, et, particulierement, en collaboration avec Teresa Palet Plaja, Capbreu de la baronia d'Entença (s. XIV). Introduccio historica $i$ estudi lingulistic. IET, T, 1987, 261 p.

18. J.-M. Font Rius, La comarca de Tortosa a raiz de la Reconquista cristiana (I148), "Cuademos de Historia de Espeña", XIX (1953), p. 104-128, retd. dans Estudis sobre drets $i$ institucions locals en la Catalunya medieval, dCja citt, p. 75-92; R. Argemí, Els tagarins a la Ribera d'Ebre al segle XIII, mémoire de licence presenté à la Faculté de Philologie, section de Langues Sémitiques, de l'Universitte de Barcelone, 1972; R. Mayordomo Font, Notas históricas sobre la camicerfa de la aljama sarracena de Tortosa (siglo XIV), citt note 9. Cf. Également E. Bayenti, Historia de Tortosa y su comarca, Tortosa, 1933-1934, 2 vol.

19. F. Macho y Ortega, Documentos relativos a la condicion social y jurddica de los mudejares aragoneses, "Revista de Clencias Juridicas y Sociales", 5 (1922), p. 143-160, 444-464 ; Condicion social de los mudejares aragoneses (siglo XV), "Memorias de la Facultad de Filosoffa y Letras de la Universidad de Zaragoza", 1 (1923), p. 137-319.

20. J. M. Lacarra, Introducción al estudio de los mudéjares aragoneses, "AEM.EES", 11, p. 7-22, et dans I SIM, M-Teruel, 1981, p. $17-28$.

21. M. L. Ledesma, La pervivencia del mundo islámico en Aragón : los mudejares, dans Historia de Aragón, 3, Z, Guara, 1986, p. 149-183, et Los mudéjares aragoneses : de la convivencia a la nuptura, dans Destierros Aragoneses, 1, Judíos y Moriscos, Z, IFC, 1988, p. 171-188.

22. M.-J. Viguera, Documentos mudéjares aragoneses, dans Gli Arabi nella Storia, Atti del XIII Congresso dell'Union Européenne d'arabisants et d'islamisants, "Quaderni di Studi Arabi", 5-6 (1988), p. 786-790.

23. M.-L. Ledesma, Los mudéjares aragoneses : de la convivencia a la ruptura, p. 175.

24. G. Colás Latorre, Los moriscos aragoneses y su expulsion, dans Destierros Aragoneses, p. 189-216.

25. Cf. une carte des établissements mudéjars en Aragon, dans J.-M. Lacara, Aragón en el pasado, Banco de Aragón, Z, 1960.

26. Sur les musulmans de Huesca, cf. M. B. Basánez Villaluenga, La aljama sarracena de Huesca en el siglo XIV, cité note 9 ; sur ceux du pays de Huesca, cf. J.-F. Utrilla et C. Esco, La población mudejar en la Hoya de Huesca (siglos XII y XIII), III SIM, 1986, p. 187-208. Sur les documents arabes provenant de cette zone, cf. J. Bosch, Los documentos árabes del Archivo de la Catedral de Huesca, "Revista del Instituto de Estudios Islámicos", 5(1957), p. 1-48, ainsi que A. Durán Gudiol, Colección diplomatica de la Catedral de Huesca, Z, 1965-1969.

27. Cf. C. L. Vega y de Luque, La morería de Teruel en el siglo XV, "Teruel", 52 (1974), p. $53-91$; M. L. Ledesma, Morabedi de Teruel y sus aldeas, 1384-1387, Z, 1982, et Los mudejares aragoneses : de la convivencia a la ruptura, dans Destierros Aragoneses, p. 177 ; A. Gargallo, La carta puebla concedida por el Temple a los moros de Villastar (1267), III SIM, 1986, p. 209-220 ; A. Novella et V. Ribot, Los mudéjares de Teruel, ibid., p. 245-251.

28. Cf. A. González Palencia, Notas sobre el régimen de riegos en la región de Veruela en los siglos XII y XIII, "AA", $\mathrm{X}$ (1945), p. 79-88; E. García Manrique, Las comarcas de Borja y Tarazona y el somontano del Moncayo. Estudio Geográfico, Z, 1960 ; J. L. Corral Lafuente, El obispado de Tarazona en el siglo XIV : El libro de Chantre : 1 . Documentacion, Tarazona, 1980 ; J. C. Escribano Sánchez, La mezquita mudéjar de Torrellas (Zaragoza), "Turiaso", V (1984), p. 293-301 ; T. Anaga, Aportaciones documentales para el estudio del urbanismo en Tarazona, ibid., VI (1985), p. 201 et sujvantes; J. Vallejo Zamora, Los moriscos de Torrellas entre 1495-1610. Consideraciones demográficas, ibid, VII (1987), p. 283-324, qui inclut la liste des noms des moros du recensement de 1495. Sur les documents en arabe de la zone, cf. M. García-Arenal, Documentos árabes de Tudela y Tarazona, "AQ", III (1982), p. 27-72, et Un nuevo documento árabe de Tudela, año de 1509, "AQ", V (1984), p. 455-462.

29. Cf. M.-L. Ledesma, La población mudéjar en la vega baja del Jalón, Miscelánea ofrecida al Ilmo. St. D. José M. Lacarra y de Miguel, Z, 1968, p. 335-351 ; M.-J. Viguera, Dos nuevos documentos árabes de Aragón (Jarque y Morés, 1492), "AEMEES", IV (1986), p. 235-261 ; A. Labarta, La aljama de los musulmanes de Calatorao nombra procurador (documento árabe de 145I), "AQ", IX (1988), p. $511-518$; O. Cuella, Los mudéjares de la comunidad de Calatayud a fines del siglo XIV y comienzos del XV, Actas del segundo encuentro de estudios bilbilitanos, II, Centro de Estudios Bilbitanos, IFC, 
Calatayud, 1989, p. 209-225; C. de la Fuente Cobos, La morería de Terrer hasta comienzos del siglo XIV, ibid., p. 251257 ; G. López Sampedro, Medallones mudejares desconocidos en Calatayud, ibid., I, p. 257-269 ; E. Marín Padilla, Los moros de Calatorao, lugar aragonés de señorio, en los siglos XIV y XV, “AQ”, IX (1988), p. 249-295, et X (1989), p. 175214.

30. Cf. J.-L. Corral, Historia de Daroca, Z, 1983 ; A. Labarta, Reconocimiento de tutela a un mudejar de Daroca : documento árabe de 1477, "AEM.EES", 5 (1983), p. 207-215 ; M. D. Pérez González et F. Mañas Ballestín, Los mudéjares del valle medio del Jiloca, III SIM, Actas (Teruel, 1984), IETur, Tenuel, 1986, p. 221-243 ; L. M. Jimeno Ortuño, Notas hist6ricas sobre la aljama sarracena de Daroca durante el último tercio del siglo XIII, cité note 9.

31. M.-L. Ledesma, La carta-puebla de María del Huerva otorgada por Alfonso el Batallador, "EEMCA", IX, Z, 1973, p. 455-463 ; Notas sobre los mudéjares del valle del Huerva (siglos XII al XIV), "AEM.EES", III (1980), p. $7-27$; J. A. Souto Lasala, De nuevo sobre musulmanes y mudéjares en el Valle del Huenva (Zaragoza) : Consideraciones en tomo a los topónimos "Novells", "Maria" y "Cadrete", ibid., VI (1984), p. 7-18.

32. M. Gómez de Valenzuela, La aljama de Letux y el concejo de Pertusa : los vasallos musulmanes y cristianos de Don Pedro de Bardaxi en 1453, dans Destierros Aragoneses, cité, p. 273-290. Cf. également M. Plou Gascón, Historia de Letux, Ayuntamiento de Letux, Z, 1989, 415 p.

33. C. Laliena, El señorío de la orden de Calatrava en el bajo Aragón en la Edad Media, thèse de doctorat inédite.

34. M.-L. Ledesma travaille actuellement sur la commanderie de Pina et Fuentes de Ebro, appartenant à l'Ordre de l'Hôpital. Sur la morería de Saragosse, cf. M.-L. Ledesma et M.-I. Falcón, Zaragoza en la Baja Edad Media, Z, 1977 ; M. I. Falcón, Zaragoza en el siglo XV, Z, 1981, et dans Historia de Zaragoza, Z, 1986, les chapitres consacrés au Moyen Age, de J.-M. Lacarra et J.-M. Canellas. Sur Caspe, cf. G. Colás, La bailia de Caspe en los siglos XVI y XVII, Z, 1979, bien que centre sur la période morisque.

35. Regina Sainz de la Maza et moi-même avons travaillé à localiser les documents, tandis que Blanca Basáñez rédige les regestes. María Echaniz s'est chargé de la recherche et de la rédaction des régestes pour deux séries de registres.

36. R.-I. Burns, El reino de Valencia en el siglo XIII (Iglesia y Sociedad), Val, Del Cènia al Segura, 1982, 801 p. (trad de The crusader Kingdom of Valencia, Harvard U.P., 1967) ; Le royaume chrétien de Valence et ses vassaux musulmans (1240-1280), "Annales. Economies. Sociétés. Civilisations" 28 (1973), p. 199-225; Islam under the Crusaders : Colonial Survival in the Thirteenth-Century Kingdom of Valencia, Princeton U.P., 1974, 475 p. ; Spanish Islam in Transition : Aculturative Survival and its Price in the Christian Kingdom of Valencia, 1240-1280, dans Islam and Cultural Change in the Middle Ages, éd. Sperios Vryonis Jr., Wiesbaden, 1975, p. 87-105; Colonialisme medieval. Explotació postcroada de la Valencia islamica, Val, Tres i Quatre, 1987 (trad. de l'éd. anglaise, Princeton U.P., 1975); The Muslim in the Christian Feudal Order : the Kingdom of Valencia, "Studies in Medieval Culture", V (1975), p. 105-126; Immigrants from Islam : The Crusaders' Use of Muslims as Settlers in Thirteenth-Century Spain, "AHR" 80(1975), p. 21-41; Moors and Crusaders in Mediterranean Spain. Collected Studies, Londres, Variorum Reprints, 1978, 318 p. ; Jaume I i els valencians del segle XIII, Val, Tres i Quatre, 1981, 348 p.; Moros, cristians i jueus en el regne croat de Vàlencia, Val, Tres i Quatre, 1987 (trad. de Muslims, christians and Jews..., Cambridge U.P., 1984) ; Societat $i$ documentació en el regne croat de Valencia. Diplomatari del regne croat de Valencia. Els documents registrats de Jaume I el Conqueridor, 1257-1276, I. Intraduccio, Val, Tres i Quatre, 1988, 369 p. (trad. de Diplomatarium of the Crusader Kingdom of Valencia, Princeton U.P., 1985); The Mudejars of Medieval Valencia : a Unique Comunity of Islam, dans Islam, Continuity and Change, Rome, Centre d'Etudes pour le Monde Arabe Modeme, 1987, p. 23-33; Els Mudejars del Regne de Valencia de la generací́ posterior a la croada, dans Història del País Valencia, II, B, Edicions 62, 1989, p. 139-167. Les autres publications sont citces dans d'autres notes, ou bien sont reprises dans des volumes de mélanges.

37. M. Gual Camarena, Mudéjares valencianos. Aportaciones para su estudio, "Saitabi" (1949), p. 165-199; Los mudéjares valencianos en la época del Magnánimo, IV Congreso de Historia de la Corona de Aragòn (Majorque, 1955), I, Palma de Majorque, 1959, p. 467-494 ; L. Piles Ros, La situación social de los moros de realengo en la Valencia del siglo XV, "Estudios de Historia Social de España", I (1949), p. 225-274; Estudio documental sobre el bayle general de Valencia, su autoridad y jurisdicción, Institutución Alfonso el Magnánimo, Val, 1970, 390 p. ; F. A. Roca Traver, Un siglo de vida mudéjar en la Valencia medieval (1238-1338), "Estudios de Edad Media de la Corona de Aragón", V (1952), p. $229-251$.

38. D. Bramon, Contra moros i jueus. Formació i estratègia d'unes discriminacions al País Valencia, Val, Tres i Quatre, 1981, 215 p. (trad. en castillan, Ed. 62, 1986) ;C. Barcelo Torres, Minorias islamicas en el País Valenciano. Historia y dia. lecto, Faculte de Philologie de l'Université de Valence et Institut Hispano-Arabe de Culture, Val, 1984, 399 p. ; M. D. Meyerson, The Mustims of Valencia in the age of Femando and Isabel. Between Coexistence and Crusade, Berkeley-Los Angeles, University of California Press, 1991, 372 p.

39. Cf. supra, note 9.

40. C. Barcel6, Toponímia aràbica del País Valencià. Alqueries $i$ castells, Val, 1983, 307 p. ; A. Labarta, La onomástica de los moriscos valencianos, CSIC, M, 1987, 255 p. ; C. Barcelo, Nuevos fondos arábigos valencianos : la colección Martinez Aloy, "AQ", VII (1986), p. 321-330; C. Barcelo et A. Labarta, Fondos documentales árabes de la minoria musulmana en tierras valencianas, "SAA", 4 (1987), p. 101-108; M. J. Rubiera Mata, Els toponims arabigo-catalans del Baix 
Segura (Alacant), "SAA", 6 (1989), p. 159-160. Les nombreux travaux de M. de Epalza ne peuvent tous être mentionnés ici. On les trouvera dans "SAA" et dans "Societat d'Onomàstica. Butlleti interior".

41. P. Iradiel, El segle XV. L'evolució econdmica, dans Història del Pafs Valencià, II. De la conquesta a la federació hispanica, p. 270.

42. M. Ferrandis Irles, Colección de cartas pueblas. XXXVII. Carta puebla de Vall d'Uixó, "BSCC", XII (1932), p. 33-38, 168-170, 190-192 ; H. García, El valle de Uxó y sus cartas pueblas, ibid., p. 170-176; A. García Sanz, Mudéjares y moriscos en Castellon, ibid., XXVII (1952), p. 94-114 ; P. L. Llorens y Raga, Los sarracenos de la sierra de Estida y Vall de Uxó a fines del siglo XV, ibid., XLIII (1967), p. 53-67; La morería de Segorbe. Rentas de su mezquita a fines del siglo XVI, ibid., XLIX (1973), p. 303-323 ; C. Barceló Torres, L'Alfondeguilla y Castro. La situación de los mudejares castellonenses en el siglo XIII, ibid., LVI (1980), p. 126-139; Las cartas drabes de Vilareal : revisión del panorama mudejar valenciano, "Estudios Castellonenses", 1 (1982), p. 365-397 ; K. W. Butzer, E. Butzer, I. Miralles, J. Mateu, Una alqueria islámica medieval de la sierra de Espadan, "BSCC", LXI (1985), p. 305-365; Butzer, K. W. , Butzer, E., J. F. Mateu, Medieval muslim communities of the Sierra de Espadan, Kingdom of Valencia, "Viator" 17 (1986), p. 339-420 ; V. Garcia Edo, Segorbe en el siglo XIII : notas para su estudio, Segorbe, Ayuntamiento, 1987, 140 p.; Un plet per les aigües del riu de Sonella entre la vila d'Onda i l'aljama mora de Tales (1310-1322), "Miralcamp. Butllet' d'Estudis Onders", 3 (1987), p. 75-110; Onda en el siglo XIII (notas para su estudio), Onda, Ayuntamiento, 1988, 156 p. ; G. Colon, L'Algadir d'Almenara (la Plana Baixa), dans Miscell lania d'Homenaje a Enric Moreu-Rey, B, Abbaye de Montserrat, 1988, p. 83-86; A. Ferrando i Francès, Interés historic, geogràfic i toponimic d'un informe militar sobre la Serra d'Espada (1561), "SAA", 5 (1988), p. 153-162 ; J. A. del Pozo Chacon, Reflexiones sobre la evolución social de las comunidades musulmanas de Tales y Artes, siglos XIII-XV, "Centre d'estudis Municipals d'Onda. Butlletr", 2 (1989), p. 89-104 ; M. Grau i Montserrat, Musulmans als ports de Morella (s. XIV), "SAA", 7 (1990), p. 151-155. (Il s'agit de marchands musulmans ou autres qui se rendent dans cette zone, et non de ressidents).

43. A. Duran i Sampere, Un document de la moreria de Valencia en l'any 1408, "Boletín de la Real Academia de Buenas Letras de Barcelona", VII (1916), p. 505-507 ; M. Ardit Lucas, El asalto a la moreria de Valencia en el anto 1455 , "Ligarzas", 2 (1970), p. 127-138 ; C. Barcel6 Torres, La moreria de Valencia en el reinado de Juan II, "Saitabi", XXX (1980), p. 49-71 ; F. Amigues, La céramique domestique des ateliers mudejars de Paterna (Valencia), "Mélanges de la Casa de Velázquez", XXIII (1987), p. 151-172.

44. C. Barcel6 Torres, Notas tipológicas sobre un procedimiento foral : dos cartas árabes del alamín de Benimuslem, "Algezira. Revista d'Estudis Històrics de la Ribera Alta", 2 (1986), p. 119-132 ; R. Pinilla Pérez de Tudela, Crisis tras las Germanias en la morería de Alzira a través de los impuestos reales (1500-1536), "Al-gezira”, 3 (1987), p. 119-132 ; M. Ruzafa García, Un conflicto económico y mental entre dos áreas marginadas. El fracaso del proyecto de ampliación de la morería de Alzira sobre el burdel (1457-1459), "Al-gezira", 4-5 (1988), p. 75-88.

45. J. Camarena Mahiques, Documentos para la historia de Gandia y su comarca, Gandía, Publ. del Instituto Laboral, 1959. 1961, 3 fasc., 80 p., publiant des recensements de la population musulmane etc. ; E. Hurtado Alvarez, Los valles de Seta y Travadell (Bosquejo geogrófico-histórico), Alicante, 1976; R. Bañó Almiñana, La problemàtica mudèjar en Alcoi, "SAA", 2 (1985), p. 39-47 ; J. Navarro Reig, Los mudéjares contestanos en el siglo XII, "AUA.HM", 6 (1987), p. 175-206; L. Ortiz de Gil-Mascarell, Mudéjares y moriscos de Aljorf (Albaida), "Estudis i Documents" (Ontinyent), III (1987), p. 71-75.

46. F. Mateu, Nómina de los musulmanes de las montañas de Coll de Rates del reino de Valencia en 1409, "AA", VII (1942), p. 299-335 ; J. Bosch Vila, Notas de toponimia para la historia de Guadalest y su valle, "Miscelánea de Estudios Arabes y Hebraicos", XII-XIII (1963-1964), p. 47-74 ; J. Ivars Pérez, Unas viviendas moriscas en la Cairola (la Vall d'Ebo), "SAA", 1 (1984), p. 91-101 ; J. Argente Vidal, Un libro de cuentas de las morerias del condado de Denia (1379), "BSCC", LXIII (1987), p. 285-329 ; C. Barceló Torres, Poblamiento y toponimia de la Vall de Gallinera islómica, "Saitabi", 37 (1987), p. 115-130 ; Poblament i toponomastica de la Vall de Gallinera isldmica, "Aguaits", 2 (1988), p. 5-16 ; J. Torro, Sobre ordenament feudal del territori $i$ trasvasament del poblament mudèjar. La "Montanea Valencie" (1286-1291), "Afers", 7 (1988-1989), p. 95-124 ; M. de Epalza, La tumba de un santo musulmán en Benifato, "Alcoy" (avril 1988), p.264-265) ; F. Franco Sánchez, La familia de los Sid Bono, unos santos árabes de Guadalest, ibid., p. 262-263; Identificación de la tumba de los Sid Bono en Benifato (Alicante), "SAA", 5 (1989), p. 181-186; M. J. Paternina Bono, Relación de los moros y cristianos sujetos al impuesto del morabati en lo loch de Ondara en 1404, "SAA", 6 (1989), p. 119-127.

47. P. Ibarra y Ruiz, Historia de Elche, $1^{\text {ec }}$ ed. 1895, 2` éd., Elx, Pastor Torres éd., 1982, 329 p. ; Elig. Noticia de algunas instituciones y costumbres de la Edad Media, III Congreso de Historia de la Corona de Aragón, Valence, 1923, p. 1-42 ; D. Romano, Un texto en aljamia hebraico-árabe (Elche, 1314), "Sefarad", 29 (1969), p. 313-318 ; P. Guichard, Un señor musulmán en la España cristiana: el " $r a$ 'is" de Crevillente (1243-1318), Alicante, 1976, 95 p., trad. de l'article publié dans les "Mélanges de la Casa de Velázquez", IX (1973), p. 283-334; A. Nieto Fernández, La morería de Orihuela en el siglo XV, Primer Congreso de Historia del País Valenciano (1971), II, Valence, 1980, p. 761-771; J. M. del Estal, Vasallaje del señorió musulmán de Crevillente a Jaime II de Aragon, "SAA", 2 (1985), p. 81-89; Corpus documental del reino de Murcia bajo la soberanta de Aragon : 1296-1304/5, I et II, Instituto de Estudios Juan Gil Albert, Alicante, 1985 et 1990 ; M. P. Gil Garcia, Conflictos sociales y oposición étnica: la comunidad mudéjar de Crevillente, 1420, III SIM. Actas, 
Teruel, 1986, p. 305-312 ; A. M. Poveda Navarro, Aproximación a la demografia bajomedieval de la comarca del Medio Vinalopó (Alicante), “AUA.HM”, 6 (1987), p. 31-48; M. T. Ferrer i Mallol, Les aljames sarrä̈nes de la governació d'Oriola, La frontera amb l'Islam en el segle XV. Cristians i sarrä̈ns al Pals Valencià et Organització i defensa d'un teritori fronterer. La governació d'Oriola en el segle XIV, cités note 9 ; A. Labarta et C. Barcel6, Los documentos árabes del archivo municipal de Novelda (Alicante), "Saitabi", XXXVIII (1988), p. 119-140 ; J. Hinojosa Montalvo, Cristianos, mudéjares y granadinos en la gobernación de Orihuela, Coloquio de Historia Medieval Andaluza. Relaciones exteriores del Reino de Granada, Instituto de Estudios Almerienses, Almería, 1988, p. 323-342 ; Textos para la Historia de Alicante. Historia Medieval, Instituto de Cultura Juan Gil Albert, Diputación de Alicante, Alcoi, 1990, 502 p. ; M. J. Rubiera Mata, Els topdnims arabbigo-catalans del Baix Segura (Alacant), "SAA", 6 (1989), 159-160; 0. Carbonell Cortés, Els últims sarraïs crevillentins, "Crevillente" (1990), 2 p.

48. C. Barceló, Un tratado catalán medieval de Derecho islámico : El "Llibre de la Cuna e Xara", Cordoue 1989, 123 p. Cf. également M. V. Febrer Romaguera, La organización judicial de las aljamas mudéjares valencianas y la "Suna $e$ Xara", Crónica del XIII Congreso Nacional de Cronistas de España y XVI Asamblea de cronistas oficiales del Reino de Valencia, I, Val, 1988, p. 193-217.

49. M. V. Febrer Romaguera, Los Bellv's : una dinastia mudéjar de alcadles generales de Valencia, Aragón y principado de Cataluña, III SIM, Actas, IETur, Teruel, 1986, p. 277-290.

50. M.-T. Ferrer i Mallol, La frontera amb l'Islam en el segle XV et Un procés per homicidi entre sarraïns, cités note 9. Cf. également C. R. Bakman, Mudejars in the Criminal Laws of the Furs de Valencia under Jaume I, "SAA", 4 (1987), p. 93-100.

51. M.-L. Ledesma, Los mudéjares y el cultivo de la tierra en Aragon, dans Estado actual de los estudios sobre Aragón (Tarazona, 1980), Actas, Z, 1981, p. 905-912 ; M. T. Ferrer, La carta de població dels sarrä̈s de la vall d'Aiora et Les aljames sarrä̈nes de la govemació d'Oriola, cités note 9 ; R. I. Burns, Colonialisme medieval, cité. Sur la sofra : P. Guichard, Le problème de la sofra dans le royaume de Valence au XIIr siècle, "Awraq", 2 (1979), p. 6471 ; M. de Epalza et M. J. Rubiera, La sofra ("sujra") en el Sharq Al-Andalus antes de la conquista catalano-aragonesa, "SAA", 3 (1986), p. 33-37. Sur l'apport musulman a l'agriculture imiguce : T. F. Glick,Regadío y sociedad en la Valencia medieval, Val, 1988, 414 p., trad, de l'anglais (Harvard U.P., 1970), et K. W. Butzer, J. F. Mateu, E. K. Butzer, P. Kraus, Irrigation Agrosystems in Eastem Spain : Roman or Islamic Origins ?, "Annals of the Association of American Geographers", 75 (1985), p. 479-509.

52. Cf. par ex. les comptes de l'ceuvre de San Pedro Mártir de Calatayud : O. Cuella Esteban, Aportaciones culturales y artisticas del Papa Luna (1394-1423) a la ciudad de Calatayud, Institución Fernando el Católico, Z, 1984, p. 75-193. Cf. également les articles sur l'art mudéjar dans les actes des SIM, particulièrement le I et le II.

53. Cf. entre autres J. Guiral-Hadzaiossif, L'organisation de la production rurale et artisanale a Valence au XV siecle, "Amuario de Estudios Medievales", 15 (1985), p. 415-465 ; M. T. Ferrer i Mallol, Les aljames sarränes de la govemacio d'Oriola, cité note 9, ànsi que des cuvres générales, comme celles déjà citées de R. I. Bums, Colonialisme medieval, et de C. Barcelo, Minorías islámicas.

54. J. Gutral, Valence, port méditerranéen au XV' siecle (1410-1525), Paris, Publications de la Sorbonne, 1986, 555 p. ; L'aportació de les comunitats jueva i musulmana al comerç marítim de Valencia al segle XV, "Afers", Homenatge al Dr. Sebastià Garcia Martínez, 5-6, 1987, p. 33-46; M. Ruzafa Gancia, Las relaciones económicas entre los mudéjares valencianos y el reino de Granada en el siglo XV, Coloquio de Historia Medieval Andaluza. Relaciones Exteriores del Reino de Granada, Instituto de Estudios Almerienses, Almería, 1988, p. 343-381; Els origens d'una familia de mencaders mudejars en el segle XV : Caat Ripoll (1381-1422), “Afers”, 7 (1988-1989), p. 169-188.

55. L. García Ballester, Historia social de la medicina en la España de los siglos XIII al XVI, I. La minoria musulmana y morisca, M, Akal, 1976 ; La medicina a la Valencia medieval : medicina i societat en un pais medieval mediterrani, Val, Ed. Alfons el Magnànim, 1989, 128 p. ; F. Franco Sánchez, M. Sol Cabello, Muhammad As-Safra, el médico y su época, Universite d'Alicante, 1990.

56. M.-T. Ferrer i Mallol, Els sarraïns de la Corona catalano-aragonesa en el segle XIV. Segregací i discriminacib, cité note 9. [voir]

57. A. Altisent, Conversión de un sarraceno aragonés (1449), “AA”, XXXI (1966), p. 373-376. M.-T. Ferrer i Mallol, Els sarraïns de la Corona catalano-aragonesa en el segle XIV. Segregacio i discriminació, cité note 9.

58. M.-L. Ledesma, Mudéjares tomadizos y relapsos en Aragón a fines de la Edad Media (1484-1512), "AEMEES”, VI (1984), p. 263-292.

59. M.-T. Ferrer i Mallol, Els sarraïns de la Corona catalano-aragonesa en el segle XIV. Segregacio i discriminacio, cité note 9.

60. W. Hoenerbach, Cuatro documentos mudéjares originarios de Catalutia y de Levante, Homenaje al Prof. Dario Cabanellas Rodríguez O.F.M., con motivo de su LXX aniversario, Grenade, Université, 1987, p. 369-379.

61. M.-T. Ferrer i Mallol, La frontera amb I'Islam en el segle XIV. Cristians i sarraïns al País Valencià, cité note 9. Cf. également J. E. López de Coca Castaîer, Los mudéjares valencianos y el reino nazari de Granada. Propuestas para una investigación, "En la Espar̃a Medieval. Estudios en memoria del Prof. D. Salvador de Mox6", I, Universite Complutense, 
M, 1982, p. 643-666; M. D. Meyerson, The War against Islam and the Mustims at home. The Mudejar Predicament of Valencia during the Reign of Femando el Catblico, "SAA", 3 (1986), p. 103-111. Cf. Egalement sur la hermandad, outre ce qui est déjà citte : A. Nieto Fernández, Hermandad entre las aljamas de moros y las villas de la gobemacion de Orihuela en el siglo XV, Primer Congreso de Historia del Pás Valenciano, II, Val, Universite, 1980, p. 749-760 ; J. Tornes Fontes, La hermandad de moros y cristianos para el rescate de cautivos, I SIM. Actas, M-Teruel, 1981, p. 499-508.

Pendant le temps de rédaction, traduction, correction d'épreuves, etc. la production bibliographique n'a pas cessé et cela m'oblige à ajouter quelques références nouvelles ou à en compléter d'autres. Le libre de M.L. Ledesma sur le repeuplement, cité à la première page', est déjà publié et aussi celui de Josefina Mutgé sur l'aljama de Leida ${ }^{2}$. En plus, après la rédaction de ce texte, sont parus le livre de Pierre Guichard, Les musulmans de Valence et la Reconquête (XIe-XIII' siècles) ${ }^{3}$ et aussi les actes du "V Simposio Internacional de Mudejarismo", qui s'est occupé de la fiscalité a l'égard des Sarrasins ou Mudéarst. Il faut souligner les apports de Maria Luisa Ledesma pour l'Aragon', de José Hinojosa Montalvo pour le royaume de Valence et de Pascual Ortega pour la Catalogne?. Il y a des travaux centrés sur l'étude d'un impôt, comme ceux d'Anna Domingo sur les "subsides" au roi dans toute la Couronne catalano-aragonaise, ou de Marfa Lutgarda Ortells sur la dîme et autres impôts de sortie du pays payés par les Sarrasins au royaume de Valences. Sont plus nombreuses les études sur localités concrètes, comme ceux de M. Inmaculada Fernández Jiménez ${ }^{9}$, F.J. García Marco ${ }^{10}$, Vidal Muñoz Garrido ${ }^{11}$, P. PÉrez Viñuales ${ }^{12}$. M.V. Febrer Romaguera a étudié des aspects institutionnels des aljamas et les competences fiscales des autorités mudéjares dans le royaume de Valence ${ }^{13}$. D'autres travaux récents ont été réalises par M. Jesús Viguera Molins sur documents mudéjares ${ }^{14}$, J. Pellicer et J.I. SGenz Diez ${ }^{15}$ Tomàs Peris Albentosa ${ }^{16}$ et Manuel Ruzafa ${ }^{17}$. Il faut aussi prendre en considération deux articles que je n'avais pu consulter, ceux de Miquel Bancelo et Mikel de Epalza publies dans un volume sur le débat interculturel dans le Bas Moyen Age's.

1. Cartas de población del reino de Aragón en los siglos medievales, Z, IFC, 1991, 543 p.

2. J. Mutge i Vives, L'Aljama sarraina de Lleida a l'Edat Mitjana. Aproximació a la seva historia, B, CSIC. IMF, 1992, $425 \mathrm{p}$.

3. Damas, Institut Francais de Damas, 1990, 2 vols.

4. Actas del V Simposio Internacional de Mudejarismo (Teruel 13-15 septiembre de 1990), Teruel, IETur, 1991, 468 p.

5. La fiscalidad mudcjar en Aragón, p. 3-17.

6. Sefiorio y fiscalidad mudejar en el reino de Valencia, p. 105-134.

7. La fiscalidad mudejar en Cataluña, p. 171-190.

8. Los mudéjares de Valencia en el siglo XV a través de los "Delmaments dels Serrahins", p. 135-145.

9. Los mudkjares del condado de Ricla, p. 33-40.

10. Fiscalidad, freudalismo y sefforío en el mudejarismo aragonés a través del ejemplo de las comunidades del Jalón y del Jalón y del Jiloca medios (siglos XII al XVI), p. 41-63.

11. Rentas y censos pagados por los mudejares turolenses en la Baja Edad Media al Capitulo General de Racioneros, p. 75-86.

12. Presión fiscal y emigración : algunos ajemplos de aljamas mudéares aragonesas, p. 75-86.

13. Antecedentes y confirugración de los consejos de viejos en las aljamas de moros valencianas, p. 147-169.

14. Sobre manuscritos mudéjares : Documentos fechados en Aragón entre los siglos $6^{\circ}-10^{\circ}$ de la Hégira (XII-XVI d. J.C.), publie dans Manuscrits arabes en Occident Musulman. Etat des collections et perspectives de recherche, Casablanca, FRAAS, 1990, p. 15-24, et Un mapa de dacumentos mudéares y moriscos de Aragón y Navarra, publié dans Homenaje al Profesor Jacinto Bosch Vilá, Université de Granada, Departamento de Estudios semíticos, Granada, 1991, L, p. 429-433. 15. Anotaciones monetarias, de pesos y de precios en documentos mudejares valencianos, dans Il Jarique de numismatica hispano-drab, L, IEI, 1990, p. 185-189.

16. Evolució patrimonial i conflictivitat social. L'exemple de la communitat mudèixar-morisca a Alzira (1242-1614), "SAA", VIII (1991), p. 163-178.

17. Los mudéjares en el desarrollo mercantl valenciano del cuatrocientos, Revista d' Història Medieval, II (Valencia, 1991), p. 179-189.

18. Miquel Barcel6, "Per sarraïns a preicar" o l'art de predicar a audiències captives, et Mikel de Epalza, Corrents islàmics aparents $i$ amagats a la cultura catalana medieval, dans "Estudi General". El debat intercultural als segles XIII i XIV. Actes de les I Jornades de Filosofia Catalana, IX (Geronne, 1989), p. 117-132 et 107-116 respectivement. 